\title{
Er:YAG and diode laser application in implant bed preparation and implant uncovering: A case report
}

\section{Zastosowanie lasera erbowo-jagowego i lasera diodowego przy wytwarzaniu łoża implantu oraz odsłanianiu implantu - opis przypadku}

\author{
Katarzyna Świder ${ }^{1, A-D}$, Marzena Dominiak ${ }^{2, E, F}$ \\ ${ }^{1}$ Private Dental Practice, Wschowa, Poland \\ ${ }^{2}$ Department of Oral Surgery, Faculty of Dentistry, Wroclaw Medical University, Poland \\ A - research concept and design; $\mathrm{B}$ - collection and/or assembly of data; $\mathrm{C}$ - data analysis and interpretation; \\ $D$ - writing the article; $E$ - critical revision of the article; $F$ - final approval of the article
}

Address for correspondence

Katarzyna Świder

E-mail: katarzyna.swider.dent@gmail.com

Funding sources

None declared

Conflict of interest

None declared

Received on June 28, 2018

Reviewed on 0ctober 29, 2018

Accepted on November 28, 2018

Published online on February 4, 2019

\begin{abstract}
The use of lasers in the field of dentistry has increased recently. Their numerous advantages and applications in soft and hard tissue surgeries make them a great alternative to conservative methods in dental implantology. The most commonly used lasers are diode and erbium-doped yttrium aluminium garnet (Er:YAG) lasers. The Er:YAG laser can be used in implant bed preparation, as it brings no thermal injury to the bone. The laser does not cause bone necrosis and positively affects osseointegration and the healing process. The use of the diode laser in soft tissue surgeries helps to obtain optimal hemostasis. Therefore, it can be used in implant exposure, since it allows performing immediate impressions.

The present case report describes the implementation of the Er:YAG laser in the implant bed preparation of a single-tooth dental implant in position 35 (according to the World Dental Federation (Fédération Dentaire Internationale - FDI) notation) for better bone regeneration. The implant exposure was performed with the diode 980-nm laser for hemostasis and immediate impressions. The results of laser employment were compared to traditional drilling and scalpel techniques. The advantages and disadvantages of the application of the above lasers were featured.
\end{abstract}

Key words: erbium-doped yttrium aluminum garnet lasers, diode lasers, blade implantation, singletooth dental implant

Słowa kluczowe: lasery erbowo-jagowe, lasery diodowe, implantacja żyletkowa, pojedynczy implant

Cite as

Świder K, Dominiak M. Er:YAG and diode laser application

in implant bed preparation and implant uncovering:

A case report. Dent Med Probl. 2019;56(1):111-116.

doi:10.17219/dmp/100386

DOI

$10.17219 / \mathrm{dmp} / 100386$

Copyright

○) 2019 by Wroclaw Medical University

This is an article distributed under the terms of the

Creative Commons Attribution Non-Commercial License

(http://creativecommons.org/licenses/by-nc-nd/4.0/) 


\section{Introduction}

The implementation of lasers has expanded recently in the field of dentistry, as they are innovative alternatives to traditional dental procedures and helpful supplementary treatment methods. ${ }^{1-3}$ The wide range of laser applications includes soft and hard tissue surgery, ${ }^{1,4,5}$ peri-implantitis treatment, ${ }^{6}$ disinfecting implant surfaces, ${ }^{6,7}$ implant exposure, ${ }^{8,9}$ and assistance in orthodontic and prosthodontic procedures. ${ }^{2,10}$ Their employment has increased notably in dental implantology. ${ }^{1,4-8}$ The most prevalently used lasers in dental clinical practices are diode and erbiumdoped yttrium aluminum garnet (Er:YAG ) lasers. ${ }^{5,6,9,11}$

Generally, besides the bone quantity and quality, the surgical implantation technique is one of the most important factors responsible for the clinical success. ${ }^{4,5,10,12-15}$ The surgical application of lasers in implant dentistry increases osseointegration and the healing process $5,13,14,16,17$ as well as shortens the treatment procedures time. . $^{1,7,7,8,10,17}$ Traditional protocols using drills can cause an interruption in the Haversian canals and Volkmann's canals, leading to the necrosis of the osteocytes, and thus to bone devitalization. ${ }^{12,13}$ However, the necrosis of the osteocytes can result not only from wrong surgical techniques. ${ }^{12,13,15}$ Bone devitalization can also happen during bone overheating at a temperature above $47^{\circ} \mathrm{C}^{15}$ and may result in complete osseointegration failure. ${ }^{12}$ Nonetheless, the correct application of the Er:YAG laser during implant bed preparation lowers the temperature of the bone compared to standard drilling methods. ${ }^{4,18-22}$ Additionally, the use of the diode or Er:YAG laser while exposing the implant allows dentists to implement immediate impressions, due to the obtained hemostasis. ${ }^{5,7,17}$ Moreover, laser irradiation of the surfaces of the implants decreases the number of bacteria living on implants and reduces the probability of infections in the peri-implant zone. ${ }^{6,7}$

As it has been described above, the use of lasers in implant dentistry has many advantages. The following case report describes a combined application of diode and Er:YAG lasers during an implantology procedure. The Er:YAG laser was employed in the implant bed preparation and the diode laser in the exposure of the implant.

\section{Case report}

A 34-year-old female patient was referred to our Private Dental Healthcare (NZOZ, Ka-Dent, Wschowa, Poland) for the extraction of tooth 35 (the World Dental Federation (Fédération Dentaire Internationale - FDI) notation used) and a single-tooth implant treatment after the bone healing period. A lateral panoramic radiograph (CS 9000 3D; Carestream Health, Inc., Rochester, USA) showed failed root canal treatment (RCT) of tooth 35 (Fig. 1). Due to the small percentage of successful conservative approaches, the decision to extract was made and the proce-

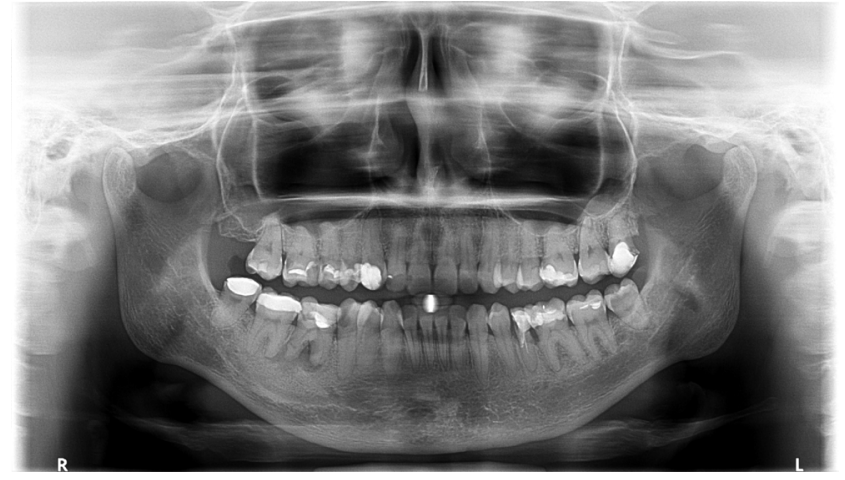

Fig. 1. Panoramic radiograph before the extraction of tooth 35

dure was performed. After a 4-month healing period, the patient returned to continue the treatment. Her medical history revealed no drug allergies, current medications, smoking, or diseases relevant to dental implantation. An intraoral examination showed good oral hygiene. Before the surgical procedure, a cone beam computed tomography (CBCT) scan was taken (CS 9000 3D; Carestream Health, Inc.) (Fig. 2). The obtained sufficient bone quantity and quality confirmed for titanium implant insertion.

The treatment plan was a single-tooth dental implant in position 35. The implant bed preparation was planned with the application of the Er:YAG laser for better bone regeneration, and implant exposure with the diode laser for immediate impressions. The patient was informed about the treatment procedures, and consent was obtained. The surgery was performed under local anesthesia (articaine hydrochloride $4 \%$ with epinephrine $1: 100 \mathrm{k}$, Citocartin ${ }^{\circledR} 100$; Molteni Dental, Kraków, Poland). The mucoperiosteal flap was elevated to gain access to the bone. The location of the implant bed was determined on the basis of CBCT, and then prepared using the Er:YAG laser (Lite Touch ${ }^{\circledR}$, Syneron Dental, Yokneam, Israel) at the following parameters set: operation mode for soft tissues (ST); energy: $300 \mathrm{~mJ}$; frequency: $35 \mathrm{~Hz}$; pulse duration: $300 \mu \mathrm{s}$; energy density per pulse: $39.79-59.68 \mathrm{~J} / \mathrm{cm}^{2}$; distilled water spray cooling: $30 \mathrm{~mL} / \mathrm{min}$; tip angle set at $10^{\circ}$; tip size: $0.8-1.3 \times 17 \mathrm{~mm}$;

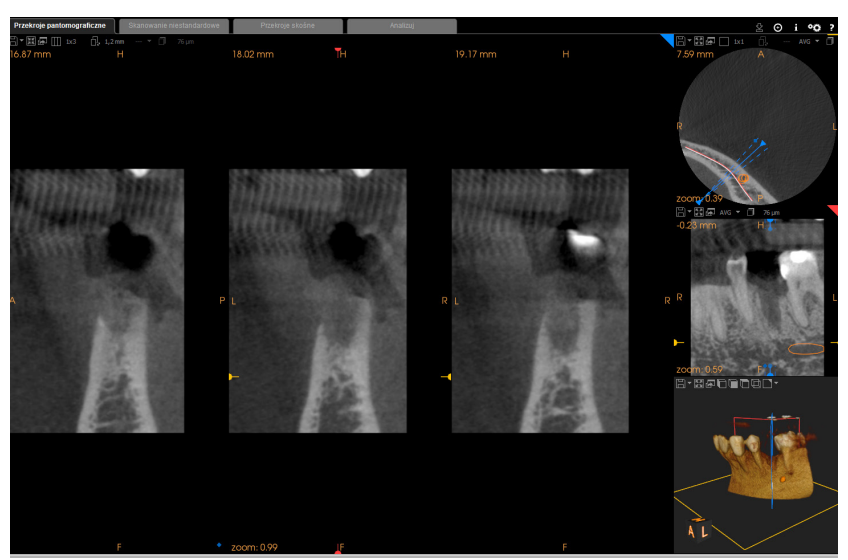

Fig. 2. Cone beam computed tomography before implant treatment, 4 months after the extraction of tooth 35 
distance: 0-2 mm (Fig. 3). The implant bed preparation was adjusted to the shape of the implant (SuperLine ${ }^{\circledR}$, Dentium Co., Ltd., Seoul, South Korea; titanium grade 4 implant, with a diameter of $4.0 \mathrm{~mm}$ and a length of $12 \mathrm{~mm}$ ) (Fig. 4). The implant bed length was evaluated with a periodontal probe. The width of the prepared implant bed was controlled by placing drills from a surgical cassette of the system utilized in this case. The final dimension of the implant bed allowed us to manually apply a drill with a diameter of $3.6 \mathrm{~mm}$ and a length of $12 \mathrm{~mm}$.

Due to photoacoustic phenomena (the cavitation effect) induced while using the Er:YAG system, the implantation site showed decreased bleeding compared to the procedure with bur cutting. The implant was inserted (Fig. 5) and non-absorbable sutures (Dafilon ${ }^{\circledR} 4.0$; B. Braun Melsungen AG, Melsungen, Germany) were used to stabilize the wound edges. Directly after the implantation, the second panoramic radiograph (Fig. 6) was taken, which confirmed the proper implant position in relation to the adjacent teeth. The primary stability measured by means

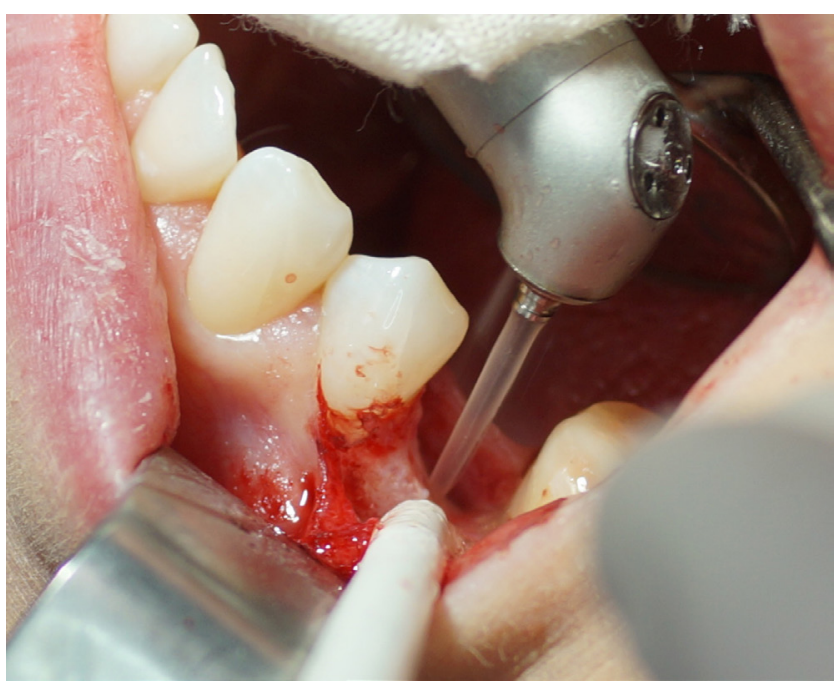

Fig. 3. Implant bed preparation using the Er:YAG laser

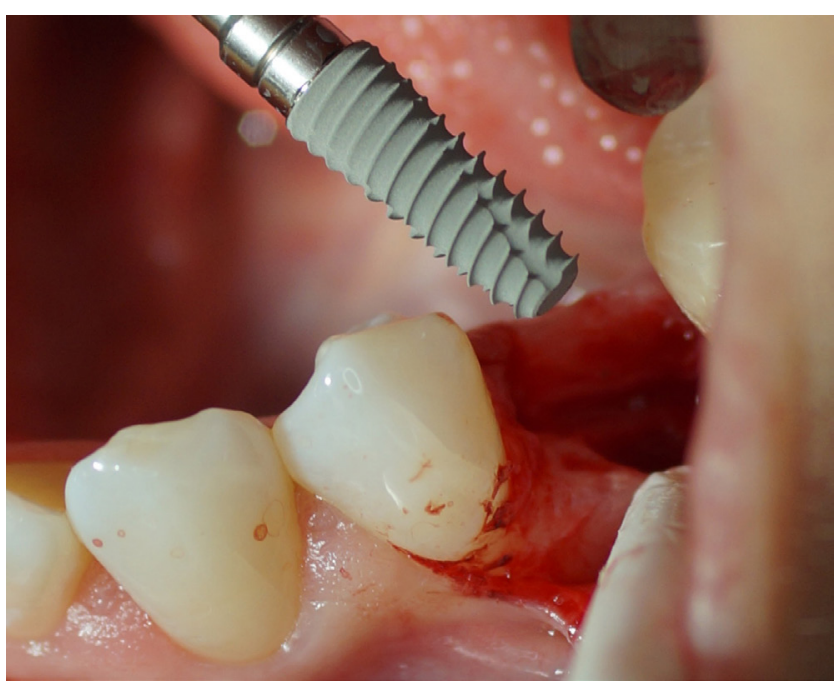

Fig. 4. Surgical site before implant placement

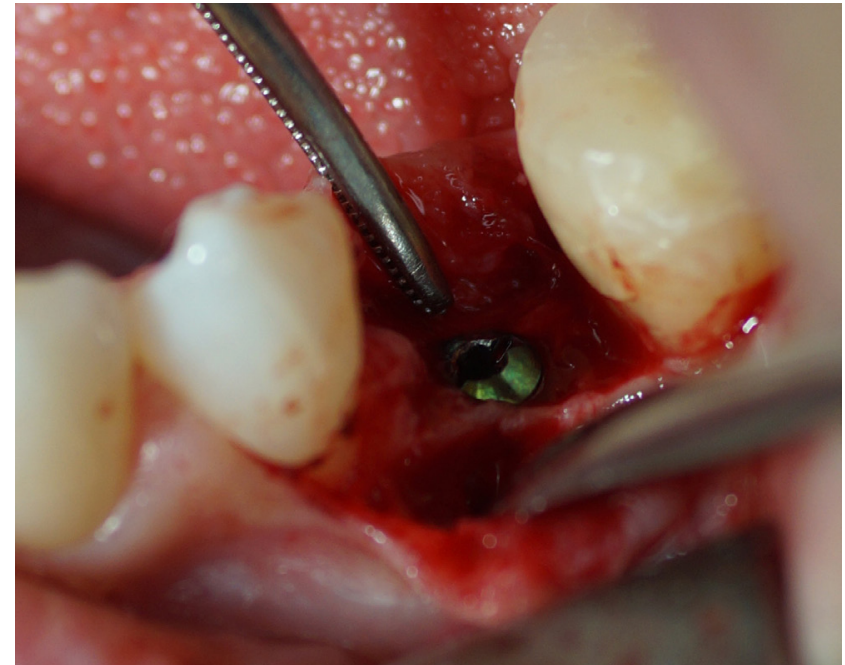

Fig. 5. Surgical site after implant placement

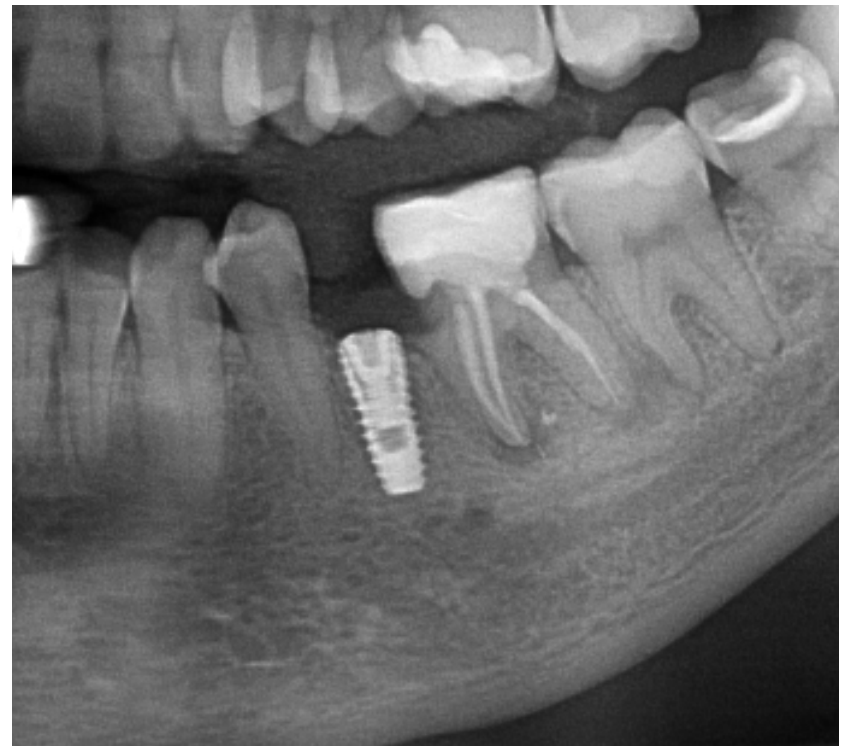

Fig. 6. Panoramic radiograph after implant placement

of the Periotest ${ }^{\circledR}$ device (Medizintechnik Gulden e. K., Modautal, Germany) was -3.6 PTV (Periotest value). The sutures were removed after 2 weeks.

After 4 months of healing, the patient reported back to continue the treatment (Fig. 7). Using local anesthesia (articaine hydrochloride $4 \%$ with epinephrine $1: 100 \mathrm{k}$, Citocartin 100; Molteni Dental), the implant was uncovered with the diode laser (GENTLEray ${ }^{\circledR}$ 980, KaVo Dental GmbH, Berlin, Germany) (Fig. 8,9). The laser operated at the following parameters set: wavelength: $980 \mathrm{~nm}$; power: $1.5 \mathrm{~W}$ in contact mode, continuous wave $(\mathrm{CW})$; distance: $0 \mathrm{~mm}$; power density: $9550 \mathrm{~W} / \mathrm{cm}^{2}$, tip angle set at $90^{\circ}$; fiber: $200 \mu \mathrm{m}$; without cooling. To gain a greater volume of the high keratinized tissue, a crescent-shaped cut in the attached gingiva (AG) around the uncovered implant was performed with the diode 980-nm laser and the flap was buccally displaced using a soft tissue elevator, which caused only minimal bleeding (Fig. 9). 
A prosthetic impression with a connected impression transfer using an open tray method was taken 2 weeks later, and

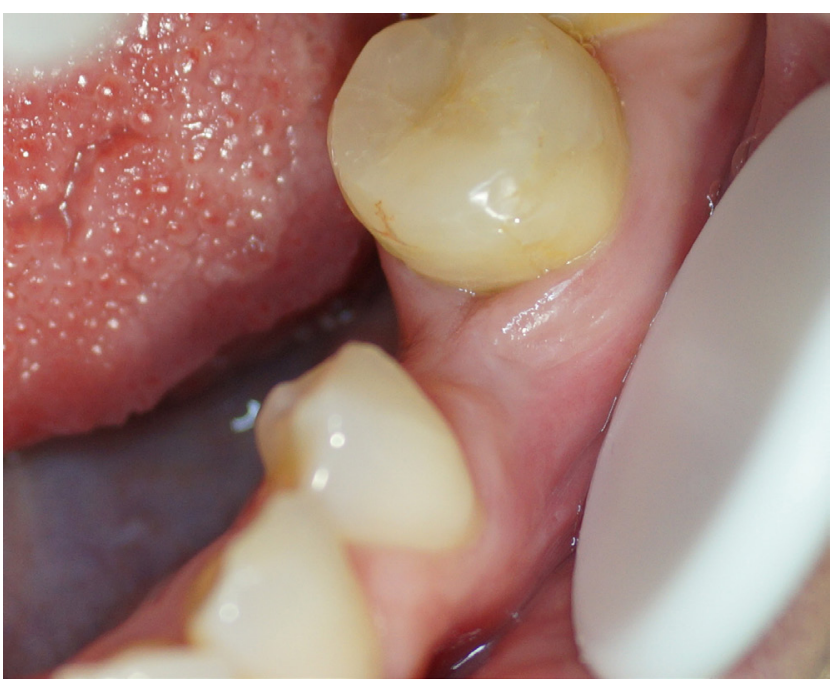

Fig. 7. Healed surgery site 4 months after implantation

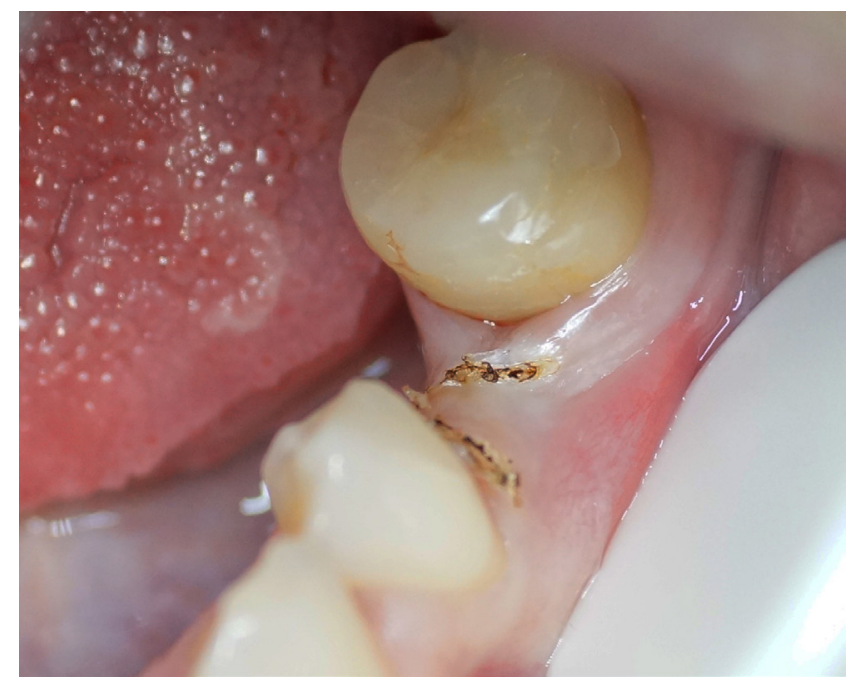

Fig. 8. Marked cutting line on the attached gingiva for implant uncovering using the diode laser

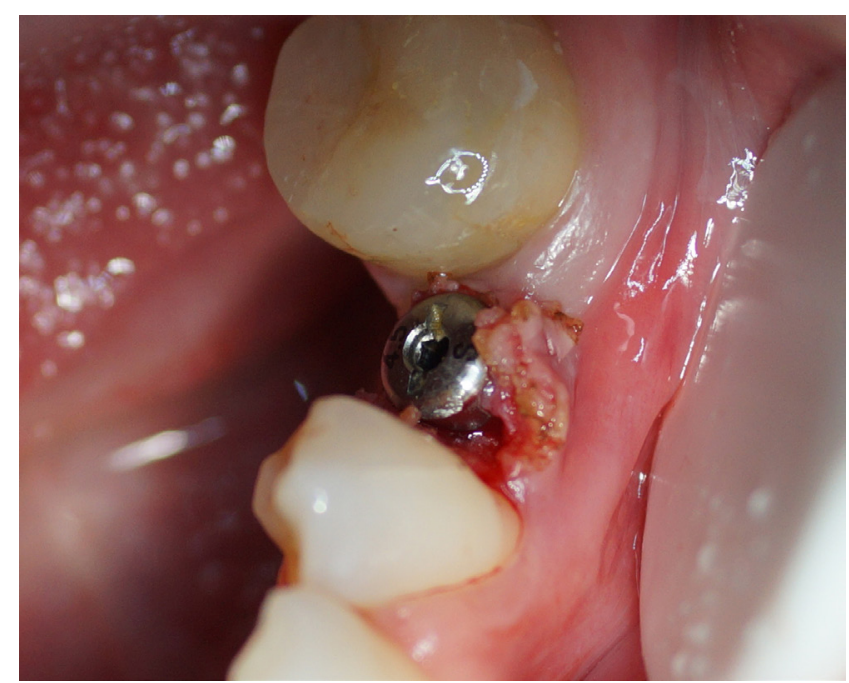

Fig. 9. Buccally displaced attached gingiva around the uncovered implant then after 3 days, a coupling was mounted onto the implant and the final prosthetic crown was cemented (Fig. 10,11).

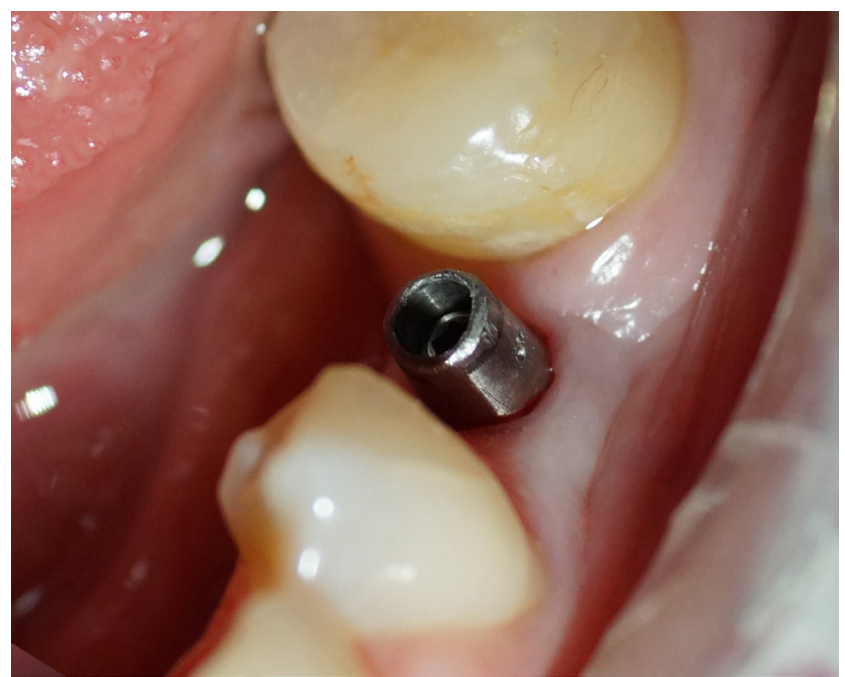

Fig. 10. Coupling mounted on the exposed implant

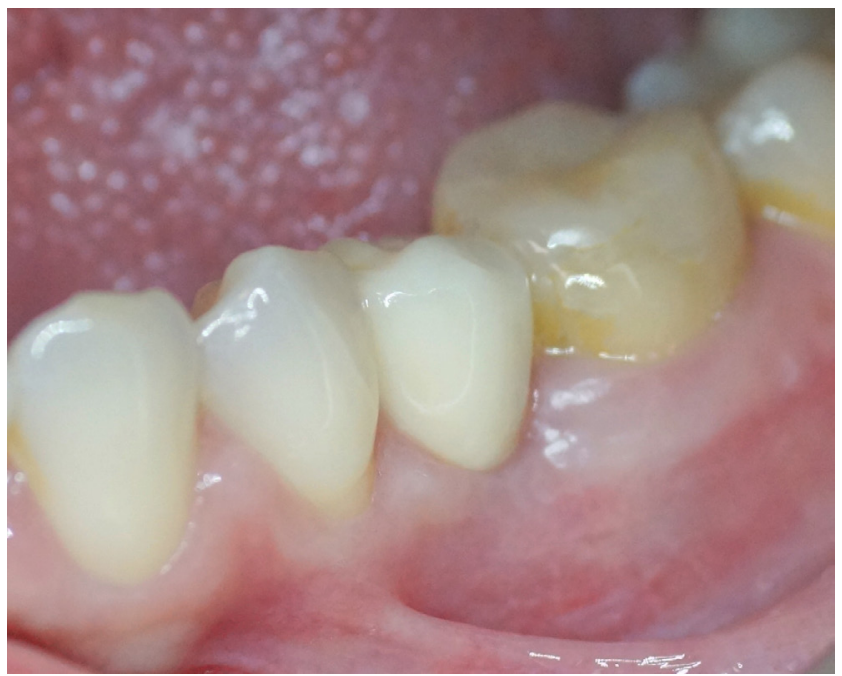

Fig. 11. Cemented final prosthetic crown

\section{Discussion}

The implementation of the Er:YAG laser in implant dentistry has many advantages. A study by Zeitouni et al. has proven that the Er:YAG laser causes less thermal tissue damage, trabecular compaction and carbonization than conventional drilling techniques. ${ }^{23}$ Although different studies reported that piezosurgery and drilling methods, when implemented correctly, did not cause thermal injury above the critical temperature, ${ }^{18,19,21,23}$ their studies show that the Er:YAG laser causes a lower increase in the bone temperature ${ }^{18,19,23}$ as well as in the soft tissue temperature. ${ }^{21}$ Similar findings were reported by other researchers. ${ }^{4,20}$ Therefore, no bone devitalization and necrosis occurs after the surgery. ${ }^{12,13,15}$ The Er:YAG laser generates light at an energy level that is readily 
absorbed by water, and thus minimizes carbonization and the necrosis of the adjacent tissue. ${ }^{20}$ Additionally, the small-diameter decortication performed by means of the Er:YAG laser appears to provide better primary stability as compared to drill and piezosurgery. ${ }^{9}$ The use of the laser results also in minimized deformation of bone tissue, precision in osseous preparation and accelerated healing. ${ }^{18,19,21-23}$ Furthermore, Baek et al. reported that the Er:YAG laser could partially diminish bleeding, which in turn could contribute to healing and therefore better osseointegration. ${ }^{24}$ The application of the Er:YAG laser has also been confirmed useful in implantations near the maxillary sinus, since it reduces the risk of the iatrogenic perforation of the Schneiderian membrane. ${ }^{19}$

Although there are many studies demonstrating the application of lasers in bone and soft tissue surgery during dental implantation, ${ }^{1-5,17-24}$ only few evaluate their advantages in implant bed preparation. ${ }^{25-29}$ The research by Seymen et al. compared the differences between the planned and prepared implant beds for the erbium, chromium-doped yttrium scandium gallium garnet (Er,Cr:YSGG) laser group and the conventional drilling group in coronal and apical deviations. ${ }^{25}$ The differences in the mean angular, coronal and apical deviations were reported to be marginally in favor of traditional drilling methods. However, the researchers considered the deviations clinically insignificant and described laser employment as a feasible method for implant bed preparation with desired depth, angle and diameter. ${ }^{25}$ However, implant bed preparation using lasers entails some disadvantages. ${ }^{25-27}$ The biggest drawback in laser osteotomy are wider peri-implant gaps, especially in the apical areas of the cavities, compared to conventional drilling. ${ }^{26,27}$ Stübinger et al. reported that even a slight angulation of the laser beam direction can lead to a severe bone loss in the implant bed. To eliminate the peri-implant gaps, an individual template can be used. ${ }^{28}$ Nevertheless, this method still excludes depth control. To eliminate both of the drawbacks mentioned above, Seymen et al. presented the employment of a stereolithographic (SLA) surgical guide for guiding the laser handpiece. ${ }^{25}$ The described technique allowed not only for a desired angle of the implant bed preparation, but also for depth control. Additionally, Ingenegeren listed several factors needed for proper implant bed preparation using lasers: the laser tip needs to be longer than the implant, there must exist congruence between bone preparation and the shape of the implant (less critical with the utilized conical and self-tapping implants than with the cylindrical types), and the bone must be properly cooled with the water spray system of the laser. ${ }^{29}$ Following the above instructions helps to achieve clinical success. ${ }^{29}$ However, it should be also underlined that in our presented case, the main difficulty during implant bed preparation was the lack of precision regarding the assessment of the width and length of the prepared bed.
A crucial factor in the success of implant-prosthetic treatment, among others, is implant osseointegration. Factors influencing osseointegration are, e.g., dental implant composition, implant design, bone heat, bone contamination, primary stability, bone quality, soft tissue status, and loading time. ${ }^{14} \mathrm{~A}$ modern high-power laser working in the wavelength of $3000 \mathrm{~nm}$ allows cutting both soft and hard tissues without visible thermal damage, due to the vaporization effect. It should be underlined that clinicians can use the Er:YAG laser not only for superficial vaporization of different tissues, but also for cutting, especially soft tissue, similar to cutting with a scalpel when using special chisel-type tips, without visible necrosis along the cutting line. ${ }^{8,9}$ Implant bed preparation with low thermal damage at the bone level as well as other abovementioned factors are essential for short and long-term success of the treatment described in our present paper.

Additionally, the quantity and quality of AG around the prosthetic restoration supported on implants are important factors in maintaining the restoration., 80 The sufficiency of AG around fixed restorations is the key factor in choosing a technique for uncovering implants. The minimum of $2 \mathrm{~mm}$ in thickness of the keratinized tissue (TKT) and in height of the keratinized tissue (HKT) is required for implant uncovering without subepithelial connective tissue grafts (SCTG) or free gingival grafts (FGG). ${ }^{8}$ The precision of lasers (small cut width) during implant uncovering allows minimal interference in AG.

Lasers in dentistry have many advantages, not only from the dentist's viewpoint but also the patient's. The combined use of Er:YAG and diode lasers will undoubtedly increase in the future. Within the limitations of the present study, it was concluded that Er:YAG laser application in implant bed preparation and diode laser employment in implant uncovering may represent a promising alternative to conventional surgical protocols. However, the authors unambiguously agree that the use of lasers is not flawless. Therefore, further clinical studies on a larger group of patients are required to evaluate their clinical limitations and long-term results.

\section{ORCID iDs}

Katarzyna Świder (D) https://orcid.org/0000-0002-9098-3957 Marzena Dominiak (1) https://orcid.org/0000-0001-8943-0549

\section{References}

1. Grzech-Leśniak K, Nowicka J, Pajączkowska M, et al. Effects of $\mathrm{Nd}$ :YAG laser irradiation on the growth of Candida albicans and Streptococcus mutans: In vitro study [published online as ahead of print on August 25, 2018]. Lasers Med Sci. 2019;34(1):129-137. doi:10.1007/s10103-018-2622-6

2. Matys J. Shear bond strength - new reports. J Clin Diagn Res. 2015;9(6):ZL01.

3. Matys J, Dominiak M, Flieger R. Energy and power density: A key factor in lasers studies. J Clin Diagn Res. 2015;9(12):ZL01-ZL02.

4. Fornaini $C$, Merigo $E$, Vescovi $P$, et al. Different laser wavelengths comparison in the second-stage implant surgery: An ex vivo study. Lasers Med Sci. 2015;30(6):1631-1639. 
5. Elanchezhiyan S, Renukadevi R, Vennila K. Comparison of diode laser-assisted surgery and conventional surgery in the management of hereditary ankyloglossia in siblings: A case report with scientific review. Lasers Med Sci. 2013;28(1):7-12.

6. Aoki A, Mizutani K, Schwarz F, et al. Periodontal and periimplant wound healing following laser therapy. Periodontol 2000. 2015;68(1):217-269.

7. Matys J, Botzenhart U, Gedrange T, Dominiak M. Thermodynamic effects after diode and Er:YAG laser irradiation of grade IV and V titanium implants placed in bone - an ex vivo study. Preliminary report. Biomed Tech (Berl). 2016;61(5):499-507.

8. Matys J, Dominiak M. Assessment of pain when uncovering implants with Er:YAG laser or scalpel for second stage surgery. Adv Clin Exp Med. 2016;25(6):1179-1184.

9. Matys J, Flieger R, Dominiak M. Effect of diode lasers with wavelength of 445 and $980 \mathrm{~nm}$ on a temperature rise when uncovering implants for second stage surgery: An ex-vivo study in pigs. Adv Clin Exp Med. 2017;26(4):687-693.

10. Matys J, Świder K, Flieger R. Laser instant implant impression method: A case presentation. Dent Med Probl. 2017;54(1):101-106.

11. Matys J, Grzech-Leśniak K, Flieger R, Dominiak M. Assessment of an impact of a diode laser mode with wavelength of $980 \mathrm{~nm}$ on a temperature rise measured by means of k-02 thermocouple: Preliminary results. Dent Med Probl. 2016;53(3):345-351.

12. Eriksson RA, Albrektsson T. The effect of heat on bone regeneration: An experimental study in rabbit using the bone growth chamber. J Oral Maxillofac Surg. 1984;42(11):705-711.

13. Trisi P, Berardini M, Falco A, Podaliri Vulpiani M. Effect of implant thread geometry on secondary stability, bone density, and boneto-implant contact: A biomechanical and histological analysis. Implant Dent. 2015;24(4):384-391.

14. Brånemark PI. Osseointegration and its experimental background. J Prosthet Dent. 1983;50(3):399-410.

15. Eriksson RA, Albrektsson T. Temperature threshold levels for heatinduced bone tissue injury: A vital-microscopic study in the rabbit. J Prosthet Dent. 1983;50(1):101-107.

16. Yeh $\mathrm{S}$, Jain K, Andreana S. Using a diode laser to uncover dental implants in second-stage surgery. Gen Dent. 2005;53(6):414-417.

17. El-Kholey KE. Efficacy and safety of a diode laser in second-stage implant surgery: A comparative study. Int J Oral Maxillofac Surg. 2014;43(5):633-638.

18. Matys J, Flieger R, Dominiak M. Assessment of temperature rise and time of alveolar ridge splitting by means of Er:YAG laser, piezosurgery, and surgical saw: An ex vivo study. Biomed Res Int. 2016;2016:9654975.

19. Matys J, Hadzik J, Dominiak M. Schneiderian membrane perforation rate and increase in bone temperature during maxillary sinus floor elevation by means of Er:YAG laser - an animal study in pigs. Implant Dent. 2017;26(2):238-244.

20. Bornstein ES. Why wavelength and delivery systems are the most important factors in using a dental hard-tissue laser: A literature review. Compend Contin Educ Dent. 2003;24:837-848.

21. Grzech-Leśniak K, Matys J, Jurczyszyn K, et al. Histological and thermometric examination of soft tissue de-epithelialization using digitally controlled Er:YAG laser handpiece: An ex vivo study. Photomed Laser Surg. 2018;36(6):313-319.

22. Matys J, Flieger R, Tenore G, Grzech-Leśniak K, Romeo U, Dominiak M. Er:YAG laser, piezosurgery, and surgical drill for bone decortication during orthodontic mini-implant insertion: Primary stability analysis - an animal study. Lasers Med Sci. 2017;33(3):489-495.

23. Zeitouni J, Clough B, Zeitouni S, Saleem M, Al Aisami K, Gregory C. The effects of the Er:YAG laser on trabecular bone micro-architecture: Comparison with conventional dental drilling by microcomputed tomographic and histological techniques. F1000Res. 2017;6:1133.

24. Baek KW, Deibel W, Marinov D, et al. A comparative investigation of bone surface after cutting with mechanical tools and Er:YAG laser. Lasers Surg Med. 2015;47(5):426-432.

25. Seymen G, Turgut Z, Berk G, Bodur A. Implant bed preparation with an erbium, chromium doped yttrium scandium gallium garnet (Er,Cr:YSGG) laser using stereolithographic surgical guide. J Lasers Med Sci. 2013;4(1):25-32.
26. Lee SY, Piao C, Heo SJ, et al. A comparison of bone bed preparation with laser and conventional drill on the relationship between implant stability quotient (ISQ) values and implant insertion variables. J Adv Prosthodont. 2010;2(4):148-153.

27. Schwarz F, Olivier W, Herten M, Sager M, Chaker A, Becker J. Influence of implant bed preparation using an Er:YAG laser on the osseointegration of titanium implants: A histomorphometrical study in dogs. J Oral Rehabil. 2007;34(4):273-281.

28. Stübinger S, Biermeier K, Bächi B, Ferguson SJ, Sader R, von Rechenberg B. Comparison of Er:YAG laser, piezoelectric, and drill osteotomy for dental implant site preparation: A biomechanical and histological analysis in sheep. Lasers Surg Med. 2010;42(7):652-661.

29. Ingenegeren I. Full-laser implant bed preparation: Case studies using different implant systems. J Interdiscip Dentistry. 2011;1:58-66.

30. Puzio M, Błaszczyszyn A, Hadzik J, Dominiak M. Ultrasound assessment of soft tissue augmentation around implants in the aesthetic zone using a connective tissue graft and xenogeneic collagen matrix - 1-year randomised follow-up. Ann Anat. 2018;217:129-141. 